\title{
Effect of Carboxylic Acid Monomer Type on Particle Nucleation and Growth in Emulsifier-free Emulsion Copolymerization of Styrene-Carboxylic Acid Monomer
}

\author{
Mahdi ABDOLLAHI ${ }^{1,2, \dagger}$ \\ ${ }^{1}$ Division of Polymerz Science and Technology, Research Institute of Petroleum Industry (RIPI), \\ P. O. Box 18745-4163, Tehran, Iran \\ ${ }^{2}$ Department of Polymer Engineering, Faculty of Engineering, Tarbiat Modares University, \\ P.O. Box 14115-143, Tehran, Iran
}

(Received February 26, 2007; Accepted April 24, 2007; Published June 12, 2007)

\begin{abstract}
Carboxylated polystyrene latexes were prepared by emulsifier-free emulsion copolymerization of styrene with various carboxylic acid monomers (AA, MAA and IA). DLS analysis and SEM observations were used to investigate the effect of various carboxylic acid monomers on the particle formation and growth processes. It was found that number of particles per unit volume of aqueous phase $\left(N_{p}\right)$ increases with increasing hydrophobicity of carboxylic acid monomers in order of IA $<$ AA $<$ MAA. There was significant difference in polymerization rate per particle $\left(R_{p} / N_{p}\right)$ in all the experiments also. The results revealed that both particle nucleation and growth processes are dependent on the hydrophilic nature of carboxylic acid monomers. SEM studies showed that $N_{p}$ is almost constant in the particle growth stage (conversion above 10\%). Through some calculations by data obtained from DLS technique, average diameter of monomer swollen polymer particles $\left(d_{p s w o l}\right)$ of all the carboxylated polystyrene latexes at the same conversion of 0.4 was obtained to be $325.24,199.30$ and $661.02 \mathrm{~nm}$ for AA, MAA and IA respectively. Attempt was made to calculate the average number of propagating radicals per particle and to determine its relevance to the kinetics of particle growth by various carboxylic acid monomers. [doi:10.1295/polymj.PJ2006246]

KEY WORDS Carboxylated Polystyrene Latex / Emulsifier-free Emulsion Polymerization / Particle Nucleation and Growth / Dynamic Light Scattering /
\end{abstract}

Water-soluble carboxylic acid monomers such as acrylic acid (AA), methacrylic acid (MAA) and itaconic acid (IA) are widely used in emulsion polymerization for the production of carboxylated latexes used for paper coatings, textile coatings and adhesives. ${ }^{1,2}$ The incorporation of the carboxyl groups on the latex particle surface, even in small amounts, provides many advantages, such as enhanced colloidal stability, mechanical and freeze-thaw stability, rheology and adhesion to various substrates. Conventional emulsion polymer systems often use monomers that are relatively water-insoluble such as styrene and butadiene. The primary reaction locus is inside the polymer particles, and aqueous-phase polymerization is usually considered to be negligible. Many industrial reaction systems, however, employ one or more monomers that have significant water solubility. The concentration and extent of reaction of these water-soluble monomers in the aqueous phase may be significant, and conventional emulsion polymerization kinetics does not readily apply to these systems. Carboxylated latexes comprise an important class of industrial emulsion polymer systems involving water-soluble carboxylic acid monomers. Carboxylic acid monomers are often completely soluble in water. However, they will still partition to varying extents into the organic phase depending on their relative hydrophobicity. In this case, significant amounts of carboxylic acid monomer may exist in both the organic and aqueous phases.

Although the conversion of monomer to polymer in conventional emulsion polymerization systems is believed to take place primarily in the monomer swollen polymer particles, the oligomeric radicals formed in the aqueous phase can play a major role in particle nucleation and stabilization and in the characteristics of the final latex products. The number of particles formed during the reaction is closely related to the amount and type of the carboxylic acid monomer, the $\mathrm{pH}$ and the ionic strength. ${ }^{1-4}$ In addition, the particle growth process, i.e. polymerization rate per particle or equivalently average number of propagating radicals per particle is also affected by the presences of carboxylic acid monomers. ${ }^{3,5-8}$ Shoaf and Poehlein ${ }^{7,8}$ developed a model that describes the kinetics of particle growth in seeded emulsion copolymerization of styrene with acrylic and methacrylic acids. These authors confirmed the influence of events taking place in the aqueous phase on the basic mechanisms operating in the particle growth stage. The model was applied to two seeded carboxylated emul- 
sion copolymerization systems, acrylic acid-styrene and methacrylic acid-styrene. Both experimental and predicted results revealed that the reaction behavior is greatly affected by the type of carboxylic acid monomer, partition of monomer between the various phases and locus of polymerization. The mechanism for acrylic acid-styrene system was more complicated than that or the methacrylic acid-styrene system. Evidence suggested that the primary reaction locus in the acrylic acid-styrene system shifts from the particles to the aqueous phase after the hydrophobic monomer (styrene) has been consumed. Most of the reported studies in the literature for emulsion polymerization systems involving carboxylic acid monomers have focused on the overall kinetic scheme in order to predict reaction rates, copolymer composition, particle concentrations and particle size. Recently, Slawinski et $a l .{ }^{5,6}$ evaluated the average number of propagating radicals per particle during interval II of the emulsion polymerization process for seeded batch emulsion copolymerization of styrene and acrylic acid. The results indicate that $\mathrm{pH}$ generally has a minor influence on the polymerization rate and average number of propagating radicals per particle in the seeded systems. Yuan et $a l .^{9-11}$ investigated experimentally the formation of water-soluble oligomers during the emulsion polymerization of styrene-butadiene-acrylic acid and determined their relevance to the kinetics and mechanism of particle nucleation and growth. The results indicated that, in the absence of micelles, the water soluble oligomers will grow in the aqueous phase and result in more acrylic acid block dyad sequence units in the oligomer chains, owing to the higher acrylic acid concentration there. When micelles exist, the water soluble oligomers will grow in both the aqueous phase and the organic phase. In this case, fewer acrylic acid dyads will be noted. Mahdavian and Abdollahi ${ }^{3}$ investigated the effect of carboxylic acid monomer amount on both particle nucleation and growth in emulsifier-free batch emulsion copolymerization of styrene-butadiene-acrylic acid by using dynamic light scattering (DLS) technique. It was observed that the number of particles and thus polymerization rate increased with increasing the carboxylic acid monomer content. There was no significant difference in the polymerization rate per particle and thereby number of propagating radicals per particle in all experiments. The results showed that in this case particle growth process is less dependent on the acrylic acid amount in comparison with its influence on nucleation stage and then particle number.

The present article attempts to provide insight into the influence of carboxylic acid monomer type on the course of the free-emulsifier emulsion polymerization of styrene (St) in the presence of various carboxylic acid monomers. Size of monomer swollen polymer particles in the reaction conditions is one of the important parameters that control the efficiency of radical entry into the particles and radical exit coefficient from the particles. For this reason, DLS technique is used here to obtain average diameter of monomer swollen polymer particles from which the influence of carboxylic acid monomer type on particle nucleation and growth is evaluated. SEM observation is used to confirm data obtained by DLS and to investigate the variation of $N_{p}$ as a function of mass conversion for various carboxylic acid monomers.

\section{EXPERIMENTAL}

\section{Materials and Equipments}

Styrene (St) monomer from Merck Chemical Co. was washed three times with a $5 \%$ aqueous solution of sodium hydroxide followed by three times washing with distilled water and then dried over anhydrous calcium chloride. To remove the inhibitor completely, styrene was passed through activated aluminum oxide (Brockmann I standard grade, basic, 150 mesh, $58 \AA, 155 \mathrm{~m}^{2} / \mathrm{g}$ surface area, Aldrich) column. The purified styrene monomer was stored in a refrigerator until use. Acrylic acid (AA) (Aldrich) and methacrylic acid (MAA) (Merck) were distilled under vacuum to remove the inhibitor. The purified carboxylic acid monomers were stored at about $14^{\circ} \mathrm{C}$ under running tap water. Potassium persulfate (KPS) as initiator and itaconic acid (IA) monomer both from Merck Chemical Co. were used without further purification. Double distilled water was used in each polymerization recipe.

Emulsion polymerizations were carried out in a stainless steel Buchi reactor equipped with mechanical stirrer and heating system with silicon oil circulation. Number-average diameter of the monomer swollen polymer particles $\left(\mathrm{d}_{\mathrm{pswol}}\right)$ was measured by a D5000 SIEMENS dynamic light scattering (DLS) (using a He-Ne laser as light source with wavelength of $632.8 \mathrm{~nm}$ under scattering angle of $90^{\circ}$ ) at ambient temperature $\left(20^{\circ} \mathrm{C}\right)$ immediately after diluting the latexes up to about $0.01 \%$ solid content with double distilled water. Direct inversion technique (cumulants analysis) was used for obtaining average diameter and polydispersity. The polydispersity is defined as the standard deviation of the particle size distribution divided by the average value. In particle size measurements by scanning electron microscopy (SEM) (Model Stereoscan 360, Cambridge Instrument Co.), one drop of diluted latex was placed on the sample holder and then freeze-dried under vacuum for removing the water and unreacted monomers (which swell the particles). Typically 500-1000 particles were measured 
Table I. Recipe for emulsifier-free batch emulsion copolymerization of styrene with various carboxylic acid monomers ${ }^{\mathrm{a}}$

\begin{tabular}{lcccc}
\hline Ingredients & XPS1 & XPS2 & XPS3 & XPS4 \\
\hline Distilled water $(\mathrm{g})$ & 420.000 & 420.000 & 420.000 & 420.000 \\
Styrene $(\mathrm{g})$ & 100.000 & 100.000 & 100.000 & 100.000 \\
Acrylic acid $(\mathrm{g})^{\mathrm{b}}$ & 4.000 & - & - & - \\
${\text { Methacrylic acid }(\mathrm{g})^{\mathrm{b}}}^{\mathrm{b}}$ & - & 4.783 & 2.392 & - \\
${\text { Itaconic acid }(\mathrm{g})^{\mathrm{b}}}^{\text {KPS }(\mathrm{g})^{\mathrm{c}}}$ & - & - & 3.614 & 7.228 \\
\hline
\end{tabular}

${ }^{a}$ Total solid content is about $20 \%$. pH in all experiments was about 2.5 due to the presence of carboxylic acid monomer. Reaction time was 7-9h (see Figure 1) bquimolar amounts of carboxylic acid monomers were used in all experiments so that the mole fraction of acid monomers in all runs was equal to 0.0547 . ${ }^{\mathrm{c}}$ Mole ratio of initiator to monomers was constant in all the experiments.

on the micrographs. The number-average diameter of polymer particles $\left(d_{p}\right)$ was determined from these measurements, which was then used to calculate $\mathrm{N}_{\mathrm{p}}$.

\section{Polymerization Procedures}

Emulsifier-free batch emulsion polymerizations were carried out in a Buchi reactor equipped with an anchor shape mechanical stirrer, which was set at $300 \mathrm{rpm}$. All of the reactions were performed at $70{ }^{\circ} \mathrm{C}$ under $\mathrm{N}_{2}$ atmosphere. The amounts of monomers and initiator in any experiment have been mentioned in Table I. The reactor was charged under nitrogen at room temperature with all ingredients. Then emulsion polymerization was started at $70^{\circ} \mathrm{C}$.

\section{Determination of Conversion}

Solid content (SC) of latex during the progress of reaction was measured gravimetrically according to ASTM D1417 (method B). Overall mass conversion $\left(\mathrm{X}_{o v}(\mathrm{t})\right)$ was calculated according to the following equation (eq 1) for each sample. All of the obtained data have been figured out in next section.

$$
X_{o v}(t)=\frac{S C(t)-S C(\text { initial })}{S C(\text { final })-S C(\text { initial })}
$$

\section{RESULTS AND DISCUSSION}

\section{Determination of Polymerization Rat}

Overall polymerization rate per unit volume of the continuous phase $\left(R_{p}\right)$ in a batch emulsion polymerization could be determined by eq 2 .

$$
R_{p}(t)=C_{M, 0} \frac{d \theta(t)}{d t} \cong C_{M, 0} \frac{d X_{o v}(t)}{d t}
$$

Generally, when there is more than one monomer in the system, $R_{p}$ should be obtained with respect to molar conversion of monomers. We studied the kinetic of reaction in the range of $0.1-0.4$ of mass conversion. Due to low amounts of carboxylic acid monomers in the polymerization recipe, difference between molar and mass conversions will be negligible. ${ }^{3}$ It should be noted that the conversion rate $\left(d X_{o v}(t) / d t\right)$ was obtained from the slope of linear part of the weight conversion versus time curve in the interval II of emulsion copolymerization, i.e. in the conversion range of 0.1-0.4. This has ignorable deviation from that obtained in molar conversion versus time curve. As a consequence, we could consider $\mathrm{R}_{\mathrm{p}}$ based on overall mass conversion (practically obtainable) in our equations.

Although the aqueous phase plays an important role in emulsion polymerization but the particle phase is mostly the major locus for polymerization progress. Hence, the participation of propagation in aqueous phase and its effect on $R_{p}$ could be neglected. ${ }^{3,5,6}$ So $R_{p}$ is calculated from eq 3 .

$$
R_{p}=\frac{\bar{k}_{p} \bar{n} N_{p} C_{M P}}{N_{a v}}
$$

The above equation eq 3 is used to determine $\bar{n}$. $\bar{k}_{p}$ could be estimated in emulsion copolymerization correctly, which will be discussed in the next section.

\section{Particle Size and Particle Number Determination}

Generally, polymer particle diameter $\left(\mathrm{d}_{\mathrm{p}}\right)$ and particle size distribution (PSD) could be measured by SEM and TEM techniques on dry state. Number of latex particles per unit volume of the aqueous phase could be calculated form the following Equation eq 4.

$$
N_{p}=\frac{6 P / W}{\frac{\rho_{P}}{\rho_{W}} \pi d_{p}^{3}}
$$

In eq $4, \rho_{P}$ and $\rho_{W}$ would be equal to $1.044 \mathrm{~g} / \mathrm{cm}^{3}$ for carboxylated polystyrene $e^{6,12}$ and $1.00 \mathrm{~g} / \mathrm{cm}^{3}$ for water respectively. $\mathrm{P} / \mathrm{W}$ is a function of monomer to water ratio and conversion. So $\mathrm{P} / \mathrm{W}$ in emulsion polymerization systems could be calculated as below eq 5 .

$$
\frac{P}{W}=\frac{M}{W} X_{o v}
$$

We could use the following equation to obtain monomer swollen particles diameter in the batch emulsion polymerization. $^{3,13}$

$$
d_{p s w o l}^{3}=d_{p}^{3}\left[1-\frac{M_{M} C_{M P}}{\rho_{M}}\right]^{-1}
$$

In intervals I and II of emulsion polymerization model introduced by Harkins, ${ }^{14}$ the monomer still exists as a separate phase and $C_{\mathrm{MP}}$ depends only on the particle diameter. It should be noted that for polymer particles 
Particle Nucleation and Growth in Emulsion Polymerization

Table II. Some useful parameters used in the calculations

\begin{tabular}{llll}
\hline Parameter & Monomer & Amount & Reference \\
\hline$M_{M}\left(\mathrm{~g} \mathrm{~mol}^{-1}\right)$ & $\mathrm{St}$ & 104.15 & Chemical catalogue \\
$\rho_{M}\left(\mathrm{~kg} \mathrm{~m}^{-3}\right)$ & $\mathrm{St}$ & $9050\left(20^{\circ} \mathrm{C}\right)$ & 15 \\
& & $8618\left(70^{\circ} \mathrm{C}\right)$ & \\
$\rho_{p}\left(\mathrm{~kg} \mathrm{~m}^{-3}\right)$ & $\mathrm{St}$ & $1044\left(50^{\circ} \mathrm{C}\right)$ & 6,12 \\
$C_{M P}\left(\mathrm{~mol} \mathrm{dm}^{-3}\right)$ & $\mathrm{St}$ & 5.5 & 6,12 \\
$r_{S t}, r_{A A}$ & $\mathrm{St}, \mathrm{AA}$ & $0.4,0.04$ & 6,16 \\
$r_{S t}, r_{M A A}$ & $\mathrm{St}, \mathrm{MAA}$ & $0.25,0.55$ & 17,18 \\
$r_{S t}, r_{I A}$ & $\mathrm{St}, \mathrm{IA}$ & $0.35,0.37$ & 19 \\
$k_{p}\left(\mathrm{dm}^{3} \mathrm{~mol}^{-1} \mathrm{~s}^{-1}\right)$ at $70^{\circ} \mathrm{C}$ & $\mathrm{St}$ & 480 & 20 \\
$k_{p}\left(\mathrm{dm}^{3} \mathrm{~mol}^{-1} \mathrm{~s}^{-1}\right)$ at $70^{\circ} \mathrm{C}$ & $\mathrm{AA}$ & 59200 & 21 \\
$k_{p}\left(\mathrm{dm}^{3} \mathrm{~mol}^{-1} \mathrm{~s}^{-1}\right)$ at $70^{\circ} \mathrm{C}$ & $\mathrm{MAA}$ & 1208 & 22 \\
$k_{p}\left(\mathrm{dm}^{3} \mathrm{~mol}^{-1} \mathrm{~s}^{-1}\right)$ at $70^{\circ} \mathrm{C}$ & $\mathrm{IA}$ & $35.6^{\mathrm{a}}$ & 23 \\
$\alpha_{M A A}^{\mathrm{b}}$ & $\mathrm{MAA}$ & $1.01\left(25^{\circ} \mathrm{C}\right)$ & 24 \\
$\alpha_{A A} \mathrm{~b}$ & AA & $0.102\left(25^{\circ} \mathrm{C}\right)$ & 24 \\
$\alpha_{I A}{ }^{\mathrm{b}}$ & $\mathrm{IA}$ & $0.01\left(50^{\circ} \mathrm{C}\right)$ & 25 \\
\hline
\end{tabular}

${ }^{a}$ Value reported for dimethyl itaconate. It is very likely that IA has a $k_{p}$ value similar to that of dimethyl ester, although no study on this matter currently exists. ${ }^{\mathrm{b}} \alpha_{i}$ is the partition coefficient of carboxylic acid monomer $i$ between styrene and water.

greater than about $50 \mathrm{~nm}, \mathrm{C}_{\mathrm{MP}}$ is independent of particle diameter. ${ }^{12}$ Monomer phase disappears in interval III and the overall conversion will be also an effective parameter on the $\mathrm{C}_{\mathrm{MP}}$.

Two situations can be considered in determination of polymer particles diameter by using DLS technique: (i) when the conversion is near 100\%. Then, the measured particle sizes are almost equal to those obtained from SEM and TEM techniques. It is noteworthy that the hydrodynamic diameter of latex particles measured by DLS is slightly larger than those measured by SEM and TEM due to the swelling of carboxylic acid groups at the surface of latex particles. The diameter of polymer particles determined by SEM and TEM is measured on dry samples. (ii) When the conversion is low. In this case, DLS analysis gives $\mathrm{d}_{\mathrm{pswol}}$ (real diameter of polymer particles swelled with monomers under the polymerization conditions) while SEM and TEM give $d_{p}$ (diameter of dried polymer particles).

In addition to withdrawing the samples for conversion analysis, a separate sampling for DLS analysis and SEM observations were carried out at various time intervals for all experiments. Then, suitable sample for particle size analysis by DLS was selected according to conversion-reaction time data so that the conversion of sample falls in the interval II of emulsion polymerization because the kinetic parameters are calculated from experimental data obtained in steady state conditions, i.e. interval II, of emulsion polymerization wherever the $N_{p}$ is constant. However, the samples available for DLS analysis as well as SEM observations were samples with mass conversions of $8.8,52.5,67.8,97.9,98.8,99.7$ and $100 \%$.
The sample with mass conversion of $52.5 \%$ was selected for DLS analysis (see Table III) because this conversion is correspond to the interval III of emulsion polymerization wherever the $N_{p}$ is constant (see next section). Hence, $d_{p}$ could be calculated from eq 6 by $\mathrm{d}_{\mathrm{pswol}}$ obtained from DLS analysis and available data for $\mathrm{M}_{\mathrm{M}}, \mathrm{C}_{\mathrm{MP}}$ and $\rho_{M}$ (Table II). Then $\mathrm{N}_{\mathrm{p}}$ would be obtained by substitution of the calculated $d_{p}$ in eq 4 . This means that $N_{p}$ is obtainable indirectly from the data given by DLS technique, wherever the polymerization reaction has not reached to the complete conversion. Unreacted monomers will be styrene (major) and carboxylic acid monomers (minor). The percentage of carboxylic acid monomer relative to styrene in the feed is low and also it does not incorporate completely into the particle phase and mainly remains in the aqueous phase depending on the its partition coefficient (Table II). Therefore, the effect of unreacted carboxylic acid monomer in swelling of particles $\left(\mathrm{d}_{\mathrm{pswol}}\right)$ and determination of $\mathrm{d}_{\mathrm{p}}$ is negligible. Consequently $\mathrm{M}_{\mathrm{M}}$ and $\rho_{M}$ of styrene in $20^{\circ} \mathrm{C}$ (temperature in which DLS analysis has been carried out) could be inserted in eq $6 . \mathrm{C}_{\mathrm{MP}}$ in the interval II of emulsion polymerization could be considered constant because the polymer particles diameter in the all experiments is enough large. Some useful parameters, available in the literature, have been given in Table II.

It should be noted that $\mathrm{R}_{\mathrm{p}}$ was obtained from the data in the range of $10-40 \%$ conversion in all experiments (interval II of emulsion polymerization in which $\mathrm{C}_{\mathrm{MP}}$ is equal to $\left.5.5 \mathrm{~mol} \mathrm{dm}^{-3}\right) .{ }^{12}$ The major problem, which arises here, is from the insertion of $\mathrm{C}_{\mathrm{MP}}$ amount in eq $6 . \mathrm{C}_{\mathrm{MP}}\left(5.5 \mathrm{~mol} \cdot \mathrm{dm}^{-3}\right)$ could be 
Table III. Data obtained for particle nucleation stage of the emulsifier-free batch emulsion copolymerization of styrene-carboxylic acid monomer

\begin{tabular}{lcccc}
\hline Parameter & XPS1 & XPS2 & XPS3 & XPS4 \\
\hline$C_{M P}\left(\mathrm{~mol} \mathrm{dm}^{-3}\right)^{\mathrm{a}}$ & 5.5 & 4.36 & 5.5 & 5.5 \\
$X_{o v}\left(\mathrm{~kg} \mathrm{~kg}^{-1}\right)^{\mathrm{b}}$ & 0.2959 & 0.5248 & 0.3211 & 0.2798 \\
$M / W\left(\mathrm{~kg} \mathrm{~kg}^{-1}\right)$ & 0.2476 & 0.2495 & 0.2524 & 0.2553 \\
$P / W\left(\mathrm{~kg} \mathrm{~kg}^{-1}\right)$ & 0.0733 & 0.1309 & 0.0810 & 0.0714 \\
$d_{p s w o l}(\mathrm{~nm})^{\mathrm{c}}$ & 285.4 & 191.2 & 253.0 & 569.4 \\
Polydispersity $(\%)^{\mathrm{c}}$ & 2.64 & 2.38 & 2.56 & 2.84 \\
$d_{p}\left(\mathrm{~nm}^{\mathrm{d}}\right)$ & 204.3 & 151.6 & 181.1 & 407.7 \\
$d_{p}(\mathrm{~nm})^{\mathrm{e}}$ & 201.3 & 147.9 & - & 402.5 \\
$N_{p}\left(\mathrm{dm}^{-3}\right)^{\mathrm{d}}$ & $1.57 \times 10^{16}$ & $6.88 \times 10^{16}$ & $2.49 \times 10^{16}$ & $1.93 \times 10^{15}$ \\
\hline
\end{tabular}

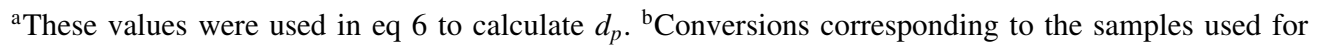
DLS analysis. ${ }^{\mathrm{c}} d_{p s w o l}$ and its polydispersity were obtained from DLS measurements. ${ }^{\mathrm{d}}$ These values were

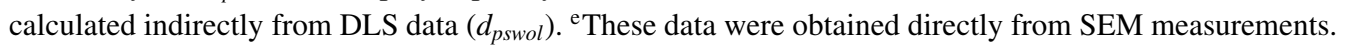

used up to $40 \%$ conversion which corresponds to the end of interval II in emulsion polymerization (see Figure 2) and then decrease with increasing the conversion. This means that $\mathrm{C}_{\mathrm{MP}}$ is dependent on the conversion in interval III. Thus its amount should be corrected for calculation of $d_{p}$ in experiment XPS2 according to the following relation:

$$
\begin{aligned}
C_{\mathrm{MP}}^{\prime} & =(1-[(52.5-40) /(100-40)]) \times 5.5 \\
& =4.36 \mathrm{~mol} \mathrm{dm}^{-3}
\end{aligned}
$$

The obtained $d_{p s w o l}$ and $d_{p}$ have been mentioned in Table III.

Estimation of $\overline{k_{p}}$ in Emulsifier-free Emulsion Copolymerization of Styrene-carboxylic Acid Monomer

In order to analyze the kinetics of reaction we could determine $\bar{n}$ by knowing $R_{\mathrm{p}}, N_{\mathrm{p}}, \bar{k}_{p}$ and $C_{\mathrm{MP}}$. Subsequently the kinetics of reaction would be discussible according to eq 3 .

The more conventional model for discussing the kinetics and chemical composition is terminal model. ${ }^{26,27}$ According to this model, $\bar{k}_{p}$ in the copolymerization reaction could be obtained as below eq 7 .

$$
\bar{k}_{p}=\frac{r_{i} f_{i}^{2}+2 f_{i} f_{j}+r_{j} f_{j}^{2}}{\frac{r_{i} f_{i}}{k_{p, i i}}+\frac{r_{j} f_{j}}{k_{p, j j}}}
$$

Mole fraction of monomers in the monomer droplets and polymer particles are the same for monomers with low solubility in water. ${ }^{28}$ However, when water-soluble monomer (such as carboxylic acid monomers) is used together with water-insoluble monomer (such as styrene, which aqueous phase solubility for this monomer at $50{ }^{\circ} \mathrm{C}$ is $4.5 \mathrm{mM}^{29}$ ) in the emulsion polymerization recipe, the mole fraction of water-soluble monomer in monomer droplets and polymer particles is determined by its partition coefficient in organic and aqueous phases. It is clear from partition coefficients of carboxylic acid monomers given in Table II that amount of MAA, AA and IA in oil (styrene) phase is about 50, 9 and $1 \%$ of initial amount respectively. As a consequence, the effect of carboxylic acid monomer concentration in oil phase on $\bar{k}_{p}$ could be neglected due to its little amount in the recipe and its very little concentration in the polymer particle phase due to high solubility in aqueous phase except MMA. Although the initial concentration of MAA in oil phase is relatively high (about $50 \%$ of initial amount, i.e. $2.39 \mathrm{~g}$ or 0.028 mole fraction in experiment XPS2 (Table I)) but the effect of its relatively high initial concentration in oil phase on $\bar{k}_{p}$ could be neglected because the propagation rate constant $\left(k_{p, M A A}\right)$ for MAA homopolymerization have not significant difference from that for St homopolymerization at the same reaction temperature (Table II). Furthermore, monomer reactivity ratios data reported in literature (Table II) suggest that the significant amount of MAA incorporates into the copolymer in the initial stage (below $10 \%$ conversion in the particle nucleation stage) of emulsion polymerization. Therefore, $\bar{k}_{p}$ was considered to be close to $480 \mathrm{dm}^{3} \mathrm{~mol}^{-1} \mathrm{~s}^{-1}$ (propagation rate coefficient of St homopolymerization) in all experiments with regard to the above assumptions and available data in Table II.

\section{Effect of Carboxylic Acid Monomer on Nucleation and Particle Growth}

DLS Studies. Jacobi ${ }^{30}$ and Priest ${ }^{31}$ published the first reports on the mechanism of homogeneous nucleation. Fitch et $a l .{ }^{32}$ and Ugelstad et al. ${ }^{33}$ proposed the quantitative theory for this phenomenon. The theoretical point of view of the homogeneous and/or coagulative nucleation was presented as Hansen-UgelstadFitch-Tsai (HUFT) theory. The mechanism of particle formation in non-micellar (such as emulsifier-free) emulsion polymerization is homogeneous and/or coagulative nucleation. According to this theory, monomeric units in the aqueous phase are added to the rad- 
icals until the obtained oligoradicals reach to their critical point in which they become insoluble in water phase. At this time they begin to precipitate and generate precursor polymeric particles. Then the monomers diffuse from their droplet phase and penetrate to the newly formed latex particles in order to swell them and propagate the polymerization reaction. These particles are colloidally unstable and have to coagulate to form the stable primary particles to compensate with this instability. Then propagation is continued in the particles that have been stabilized by ionic charges of carboxyl groups and end groups of the initiator. According to the above explanation, it is necessary to know the role of water-soluble monomers in emulsifier-free emulsion polymerization systems.

In previous paper, ${ }^{3}$ we investigated the effect of carboxylic acid amount on particle nucleation stage in emulsifier-free emulsion polymerization of styrene-butadiene-acrylic acid. It was observed that the number of particles and thus polymerization rate increased with increasing the acrylic acid amount. In the present study, we examined the effect of various carboxylic acid monomers on the homogeneous and/or coagulative nucleation stage as well as particle growth stage in emulsifier-free emulsion polymerization of styrene-carboxylic acid monomer (Table I). It should be noted that in all the experiments, there was no problem concerning stability of the obtained latexes. The results of DLS analysis revealed the narrow particle size distribution so that the polydispersity of polymer particles was always below $3 \%$. Some useful information has been summarized in Table III.

Data given in Table III reveals that the number of latex particles per unit volume of the aqueous phase $\left(N_{p}\right)$ will increase remarkably with increasing the hydrophobicity of carboxylic acid monomers (see the partition coefficients of carboxylic acid monomers in Table II) in the order of IA $<\mathrm{AA}<(\mathrm{IA}+\mathrm{MAA})<\mathrm{MAA}$ (Fig. 1). This could be attributed to the increase in number of precipitating oligoradicals during nucleation stage and prevention of particles from limited flocculation in the growth step. Some evidence for this behavior could also be found in the progress of reaction below $10 \%$ conversion, i.e. particle nucleation stage (Fig. 2). The polymerizations performed with most hydrophilic monomer, itaconic acid, had a significantly lower reaction rate. It is evident that the polymerization rate below 10\% conversion (particle nucleation stage) increases with increasing the hydrophobicity of carboxylic acid monomers since logically it should generate more stable primary particles (see the next section). It should be noted that polymerization rate in the experiments XPS2 and XPS3 increase suddenly above about $60 \%$ conversion due to the gel effect.

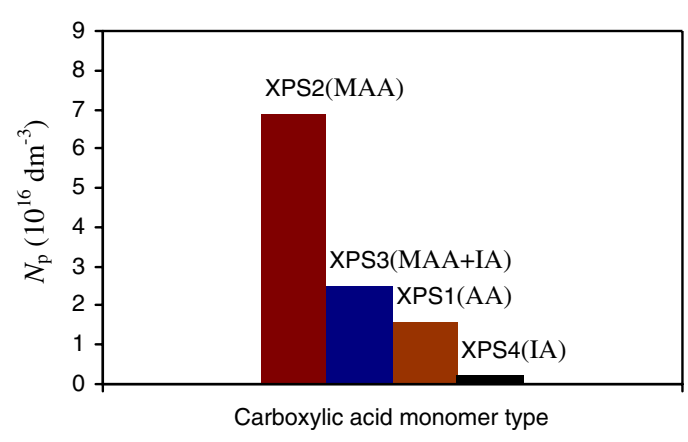

Figure 1. Dependency of the number of the polymer particles per unit volume of the aqueous phase on the carboxylic acid monomer type

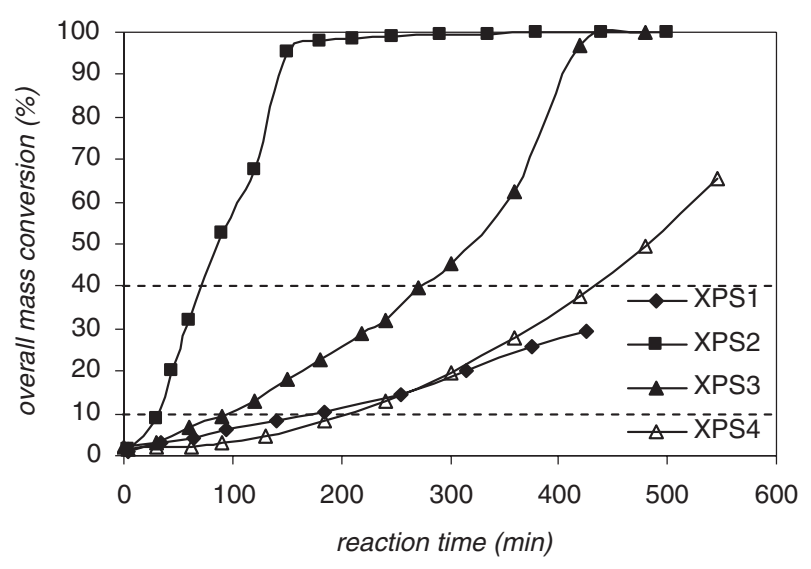

Figure 2. Overall mass conversion as a function of reaction time in emulsifier-free batch emulsion polymerization of styrene-carboxylic acid monomer

$R_{p}$ obtained from eq 2 in the conversion range of 0.1-0.4 (interval II of emulsion polymerization) and $R_{p} / N_{p}$ (polymerization rate per particle) have been given in Table IV. It is expected that at the same conditions of monomer to water ratio, diameter of polymer particles and number of polymer particles per unit volume of aqueous phase, the polymerization rate per particle decreases with increasing the hydrophilicity of carboxylic acid monomers due to the low efficiency of oligoradicals entry into the polymer particles. This expectable trend could not be seen for our experiments (Table IV) due to non-equal numbers of polymer particles per unit volume of water and thereby non-equal diameter of polymer particles. Trends observed here will be explained in detail in the next section. However, it may be deduced from above data that carboxylic acid monomer type has a significant effect on the both particle nucleation $\left(\mathrm{N}_{\mathrm{p}}\right)$ and growth $\left(\mathrm{R}_{\mathrm{p}} / \mathrm{N}_{\mathrm{p}}\right)$ processes.

SEM Studies. In addition to one sample selected from each experiment for DLS analysis, all the available samples were used in SEM observations in order to further investigating the evolution of average diam- 
Table IV. Kinetic parameters relating for particle growth stage of emulsifier-free emulsion copolymerization of styrene-carboxylic acid monomer

\begin{tabular}{lllll}
\hline Parameter & XPS1 & XPS2 & XPS3 & XPS4 \\
\hline$d X_{\mathrm{ov}} / d t\left(\mathrm{~s}^{-1}\right)$ & $1.372 \times 10^{-5}$ & $1.216 \times 10^{-4}$ & $2.860 \times 10^{-5}$ & $2.297 \times 10^{-5}$ \\
$C_{\mathrm{M}, 0}\left(\mathrm{~mol} \mathrm{dm}^{-3}\right)$ & 2.418 & 2.418 & 2.418 & 2.418 \\
$C_{\mathrm{MP}}\left(\mathrm{mol} \mathrm{dm}^{-3}\right)^{\mathrm{a}}$ & 5.5 & 5.5 & 5.5 & 5.5 \\
$R_{\mathrm{p}}\left(\mathrm{mol} \mathrm{dm}^{-3} \mathrm{~s}^{-1}\right)$ & $3.318 \times 10^{-5}$ & $2.940 \times 10^{-4}$ & $6.916 \times 10^{-5}$ & $5.554 \times 10^{-5}$ \\
$R_{\mathrm{p}} / N_{\mathrm{p}}\left(\mathrm{mol} \mathrm{s}^{-1}\right)$ & $2.113 \times 10^{-21}$ & $4.275 \times 10^{-21}$ & $2.773 \times 10^{-21}$ & $2.879 \times 10^{-20}$ \\
$\bar{n}$ & 0.482 & 0.975 & 0.633 & 6.569 \\
\hline
\end{tabular}

${ }^{\text {a }}$ These values were used in eq 3 to calculate steady state average number of growing radicals per particles $(\bar{n})$.

eter of polymer particles $\left(\mathrm{d}_{\mathrm{p}}\right)$ with conversion from which $\mathrm{N}_{\mathrm{p}}$ as a function of mass conversion was calculated via eq 4. Samples of experiments XPS1, XPS2 and XPS4 were investigated in the SEM observations (Figure 3) as the representative samples for emulsifier-free emulsion polymerization of styrene in the presence of AA, MAA and IA respectively. The results of $\mathrm{N}_{\mathrm{p}}$ versus mass conversion are given in Figure 4. It should be noted that Small and non-spherical particles in Figure 3(a) and (b), especially in Figure 3(a) may be attributed to the existence of a contamination in the SEM sample holder (mainly) or the precipitation of dead water soluble oligomers with many carboxylic acid monomer units during the freeze-drying of latex under vacuum because there was no peak in DLS analysis in the range of these small particles and particle size distribution was completely unimodal in the all experiments. Hence, these small and non-spherical particles are not related to the nucleated particles during emulsion polymerization and thus we did not measure the size of small particles in SEM micrographs. As a result, same as DLS results, the polydispersity of polymer particles size in SEM measurements (Figure 3) was always below $3 \%$, indicating the narrow distribution of polymer particles size.

It is clear from Figure 4 that at the very beginning of the emulsifier-free emulsion polymerization (below about $10 \%$ conversion), a large number of precursor particles are formed by homogeneous nucleation mechanisms, and their concentration increases with conversion. This results in a rapid increase in the number of polymer particles. With further growing the polymer particles, surface area of them increase significantly and thereby polymer particles become unstable. At this time, limited coagulation occurs (in order to stabilize the growing particles, which leads to the observed decrease in $\mathrm{N}_{\mathrm{p}}$ ) until a new stabilization condition is reached. Similar results have been observed for the emulsion copolymerization of styrene-butadiene-acrylic acid in the presence of sodium lauryl sulfate emulsifier with the concentration below critical micelle concentration (CMC) [11]. The results
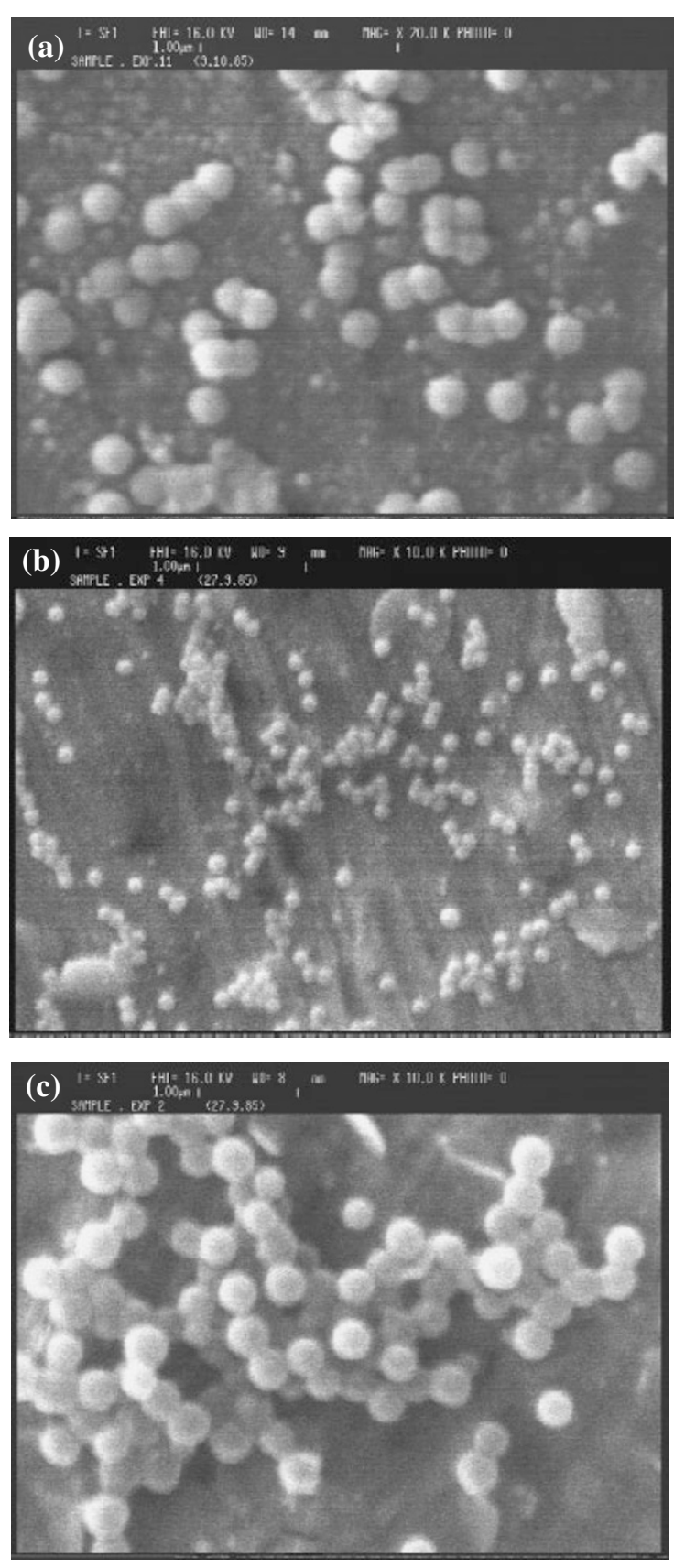

Figure 3. SEM micrographs of latexes XPS1(AA) (a), XPS2(MAA) (b) and XPS4(IA) (c) at the mass conversions of 29.59 (a), 52.48 (b) and $27.98 \%$ (c) (see Table III) 


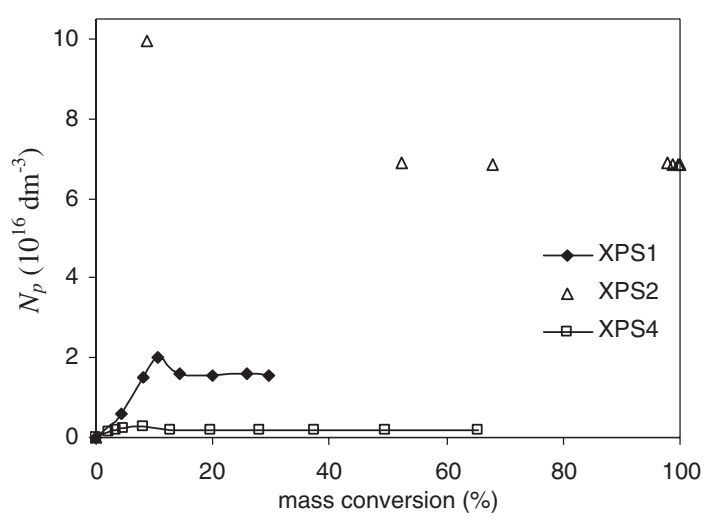

Figure 4. $N_{p}$ versus mass conversion for the emulsifier-free emulsion polymerization of styrene in the presence of AA (XPS1), MAA (XPS2) and IA (XPS4)

in Figure 4 show that homogeneous-coagulative particle nucleation is occurred in the conversions below about $10 \%$ and then $\mathrm{N}_{\mathrm{p}}$ become almost constant in the particle growth stage of emulsifier-free emulsion copolymerization of styrene-carboxylic acid monomer. Constant $\mathrm{N}_{\mathrm{p}}$ in the particle growth stage allows us to calculate the steady state $\bar{n}$ in the interval II of emulsion polymerizations by eq 3 (see next section). Moreover, comparing $d_{p}$ obtained directly from SEM technique and $d_{p}$ calculated from DLS data $\left(d_{\text {pswol }}\right)$ for the same samples (Table III) show no significant difference between them. This means that according to eq $6, \mathrm{~d}_{\mathrm{p}}$ can be calculated by $\mathrm{d}_{\mathrm{pswol}}$ data obtained from DLS measurements providing that the true value of $\mathrm{C}_{\mathrm{MP}}$ for the corresponding emulsion polymerization system is known. Therefore, DLS technique was used here to measure $d_{\text {pswol }}$ during the interval II of emulsion polymerization from which kinetic parameters in the particle growth stage $\left(\mathrm{R}_{\mathrm{p}} / \mathrm{N}_{\mathrm{p}}\right.$ and $\bar{n}$ ) as well as the effect of carboxylic acid monomers on these kinetic parameters were evaluated (see next sections). Slightly greater $d_{p}$ values in DLS measurements (Table III) are reasonable because DLS method measures hydrodynamic diameter of monomer swollen polymer particle from which $d_{p}$ is calculated while SEM measures $d_{p}$ on the dry state.

The function of the carboxylic acid monomer in emulsifier-free emulsion polymerization is twofold according to the mechanism of homogeneous/coagulative nucleation. It delays the formation of polymer particles by precipitation of oligoradicals formed in aqueous phase after critical degree of polymerization (homogeneous nucleation) and lends stability to the polymer particles. The results in Table III and Figure 4 indicate that the ability of the carboxylic acid monomers to generate particles is inversely related to their hydrophilicity (Table II), with the most hydrophilic, itaconic acid, being least effective. The similar results have been deduced from polymerization rate data for the emulsifier-free emulsion polymerization of styrene and styrene-butadiene in the presence of various carboxylic acid monomers, ${ }^{34}$ however, attempts have not been made to estimate $\mathrm{N}_{\mathrm{p}}$ and other kinetic parameters.

\section{Effect of Carboxylic Acid Monomer on the Efficiency of Radical Entry into the Particles}

Rate of emulsion polymerization in interval II (conversion range of about $0.1-0.4$ on the bases of $C_{M P}$ value reported for emulsion polymerization of styren $^{12}$ ) was almost constant in our system as can be seen in Figure 2. It could be considered that particle nucleation has been occurred before conversion of about 0.1 (Figure 4). ${ }^{9}$ Therefore, we assumed that $\mathrm{N}_{\mathrm{p}}$ is constant in intervals II and III of emulsion polymerization and thus $R_{p} / N_{p}$ was calculated during particle growth. The results, which have been given in Table IV, show that $R_{p} / N_{p}$ decreases in order of XPS4(IA) $\gg$ XPS2(MAA) > XPS3(MAA+IA) > XPS1(AA).

According to eq 3 , variation in $R_{\mathrm{p}} / N_{\mathrm{p}}$ could be related to the influence of carboxylic acid monomer type on either $\bar{k}_{p}$ or $\bar{n}$. The influence of carboxylic acid monomer type on $C_{\mathrm{MP}}$ is ruled out due to the low amounts of carboxylic acid monomer used in the recipes and its less solubility in particle phase. Moreover, on the basis of discussion in the previous section, the effect of carboxylic acid type on $\vec{k}_{p}$ is probably very limited and it could not explain differences in the observed polymerization rates per particle. So the results would be attributed to the influence of carboxylic acid monomer on $\bar{n}$. This parameter was calculated by knowing of $C_{\mathrm{MP}}$ (Table II), $\mathrm{R}_{\mathrm{p}} / \mathrm{N}_{\mathrm{p}}$ (Table IV) and $\bar{k}_{p}\left(\bar{k}_{p}=480 \mathrm{dm}^{3} \mathrm{~mol}^{-1} \mathrm{~s}^{-1}\right.$ at $70^{\circ} \mathrm{C}$, Table II $)$ via eq 3. The results are shown in Table IV.

With performing the experiments in the same experimental conditions in regard to the number of polymer particles per unit volume of aqueous phase, diameter of polymer particles and monomer to water ratio, i.e. seeded emulsion polymerization, it is expected that the polymerization rate per particle $\left(\mathrm{R}_{\mathrm{p}} / \mathrm{N}_{\mathrm{p}}\right)$ and average number of the propagating radical per particle $(\bar{n})$ decreases with increasing the hydrophilicity of carboxylic acid monomer due to the low efficiency of oligoradicals entry into the polymer particles. It is clear that critical polymerization degree of oligoradicals formed in the aqueous phase depends directly on the hydrophilicity of carboxylic acid monomers. Higher critical polymerization degree of oligoradicals formed in the aqueous phase can result in the increased concentration of oligoradicals in the aqueous phase and thereby oligoradicals may be terminated before entering into the polymer particles. As a consequence, the efficiency of oligoradicals entry into the polymer 
Table V. Diameter of monomer swollen polymer particles at mass conversion of 0.4 for emulsifier-free emulsion copolymerization of styrene-carboxylic acid monomer

\begin{tabular}{lllll}
\hline Parameter & XPS1 & XPS2 & XPS3 & XPS4 \\
\hline$P / W$ & 0.0990 & 0.0998 & 0.1010 & 0.1021 \\
$N_{p}\left(\mathrm{dm}^{-3}\right)$ & $1.57 \times 10^{16}$ & $6.88 \times 10^{16}$ & $2.49 \times 10^{16}$ & $1.93 \times 10^{15}$ \\
$d_{p}(\mathrm{~nm})$ & 225.95 & 138.46 & 194.91 & 459.24 \\
$d_{p \text { swol }}(\mathrm{nm})$ & 325.24 & 199.30 & 280.55 & 661.02 \\
$\bar{n} N_{p}\left(\mathrm{dm}^{-3}\right)$ & $7.57 \times 10^{15}$ & $6.71 \times 10^{16}$ & $1.58 \times 10^{16}$ & $1.27 \times 10^{16}$ \\
\hline
\end{tabular}

particles decreases. It should be noted that although the concentration of carboxylic acid monomeric freeradicals formed by transfer reactions in the particle phase increases with increasing the hydrophobicity of carboxylic acid monomer but at the same diameter of monomer swollen polymer particles, it is expected that desorption rate of free-radicals from polymer particles will not increase significantly because the water solubility of free-radicals decreases with increasing the hydrophobicity of carboxylic acid monomer. In the present study, diameter of polymer particles in the all experiments is not the same (Table III) and thus our results should be explained by considering simultaneously the effect of carboxylic acid monomer type as well as the polymer particles diameter on $\mathrm{R}_{\mathrm{p}} / \mathrm{N}_{\mathrm{p}}$ and $\bar{n}$ as follow.

There is a way to better understanding the effect of carboxylic acid monomer on the polymerization rate per particle and average number of the propagating radical per particle without performing the seeded emulsion polymerization. Since polymerization rate per particle in the batch emulsion polymerization is controlled by hydrophilicity of oligoradicals formed in the aqueous phase and diameter of the monomer swollen polymer particles, one can observe truly the effect of hydrophilicity of carboxylic acid monomers on the polymerization rate per particle providing that the real diameter of polymer particles under experimental conditions, i.e. the monomer swollen polymer particles diameter is considered also.

To calculate the monomer swollen particles diameter $\left(d_{p s w o l}\right)$, it was assumed that the number of particles in the interval II of emulsion polymerization (conversion range of 0.1-0.4) is constant and equal to the calculated values in Table III. This is true because the number of polymer particles remains constant in intervals II and III of emulsifier-free emulsion polymerizations (Figure 4). Then, similar conversion of 0.4 (end of interval II on the bases of $\mathrm{C}_{\mathrm{MP}}$ value of $5.5 \mathrm{~mol} \cdot \mathrm{dm}^{-3}$ ) was considered for all the experiments due to this fact that $\bar{n}$ in Table IV have been obtained from polymerization rate data in the range of $0.1-0.4$. With considering the overall conversion of 0.4 and $N_{p}$ values in Table III, $d_{p}$ was calculated by

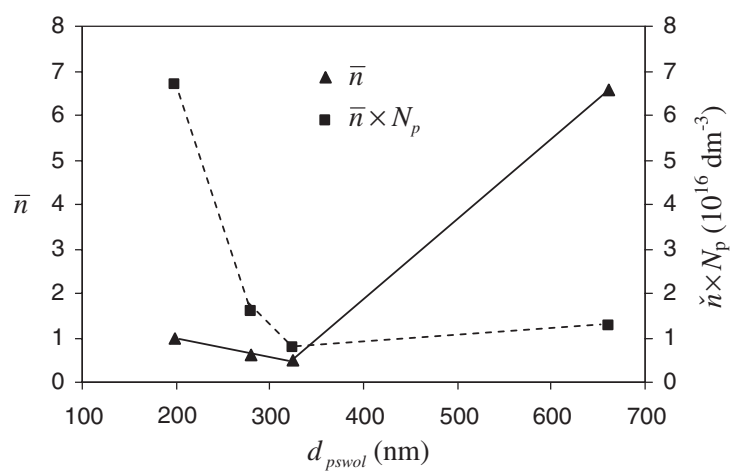

Figure 5. Average number of propagating radicals per particle $(\bar{n})$ as well as the number of propagating radicals into the all particles per unit volume of aqueous phase $\left(\bar{n} N_{p}\right)$ as a function of monomer swollen polymer particles (Table V) in emulsifier-free emulsion polymerization of styrene-carboxylic acid monomer

eq 4 and was substituted in eq 6 to calculate $d_{p \text { swol }}$. In order to estimate real $d_{p s w o l}$ under the reaction condition, $\rho_{M}$ of styrene at $70^{\circ} \mathrm{C}$ (reaction temperature) (Table II) was inserted in eq 6 . The results are given in Table V.

Average number of propagating radicals per particle $(\bar{n})$ as well as the number of propagating radicals into the all particles per unit volume of aqueous phase $\left(\bar{n} N_{p}\right)$ as a function of monomer swollen polymer particles $\left(d_{p s w o l}\right)$ are shown in Figure 5. It is clear that with increasing $d_{p s w o l}$ (real diameter of polymer particles during emulsion polymerization), number of propagating radicals per particle decrease slightly and then increase significantly in the case of IA (XPS4). According to emulsion polymerization kinetics, number of propagating radicals per particle should be increased with increasing the monomer swollen polymer particles. Nonconformity of experimental data and theoretical prediction can be attributed to the effect of carboxylic acid monomers on both particle nucleation $\left(N_{\mathrm{p}}\right)$ and growth $\left(\mathrm{R}_{\mathrm{p}} / \mathrm{N}_{\mathrm{P}}\right.$ and thus $\left.\bar{n}\right)$ (see the next section).

From Figure 5 it is clear that the number of propagating radicals into the all particles per unit volume of aqueous phase $\left(\bar{n} N_{\mathrm{p}}\right)$ decreases initially with increasing the monomer swollen polymer particles $\left(d_{p s w o l}\right)$ which related to the nature of carboxylic acid monomers and then increases slightly in the case of XPS4. Now, trends observed for $\mathrm{R}_{\mathrm{p}} / \mathrm{N}_{\mathrm{p}}$ (or $\bar{n}$ ) and $\bar{n} N_{p}$ can be explained logically as follow.

All the data available in Table IV show that the polymerization kinetic in experiments XPS2, XPS3 and XPS4 obeys Smith-Ewart kinetic (case 3) with $\bar{n}>0.5$ while emulsion polymerization in experiment XPS1 follows the Smith-Ewart kinetic (case 2) with $\bar{n} \approx 0.5{ }^{35}$ For experiments XPS1, XPS2 and XPS3, decrease in $\bar{n}$ with increasing the hydrophilicity of carboxylic acid monomer means that nature of the car- 
boxylic acid monomer influences the mass transfer phenomena and also termination rate mainly. This illustrates the low entry rate of oligomeric radicals (formed in aqueous phase) into the latex particles or increases of radical exit rate from the latex particles. The probable reason that explains the increase in radical exit by increasing hydrophilicity of carboxylic acid monomer might be transfer reactions from oligoradicals to carboxylic acid monomer. The newly formed monomeric radicals have high solubility in water and cause the increase in exit rate of free radicals from the particle phase. Thus, the greater value of $\bar{n}$ for XPS2 (MAA) relative to XPS1 (AA) (Table IV and Figure 5) can be attributed to the higher efficiency of oligoradicals entry into the polymer particle in the case of more hydrophobic MAA and to the influence of carboxylic acid monomer on radical exit from polymer particles because the transfer reaction to hydrophilic acrylic acid in XPS1 in comparison with the transfer reaction to hydrophobic methacrylic acid in XPS2 produces monomeric radicals with higher tendency to exit from polymer particles.

General trend of $\bar{n} N_{p}$ values related to the particle growth stage can be described by considering the effect of carboxylic acid monomer type on the nucleation process. $\mathrm{N}_{\mathrm{p}}$ increases with decrease in hydrophilicity of carboxylic acid monomer (Figure 1). Increase in $\mathrm{N}_{\mathrm{p}}$ will result in increase in total surface area of polymer particles. As a consequence, the total oligoradicals entered into the all particles and thereby the number of propagating radicals into the all particles per unit volume of aqueous phase $\left(\bar{n} N_{p}\right)$ will increase and thus total polymerization rate will be increased (eq 3 and Figure 2).

From above discussion, increase in $\bar{n} N_{p}$ for most hydrophilic carboxylic acid monomer (IA) in comparison with AA is unexpected but it can be explained by much higher value of $\bar{n}$ in the case of IA (Table IV) as follow. In the equimolar amount of carboxylic acid monomers, $\mathrm{pH}$ of aqueous phase in the styrene-itaconic acid will be lower than the styrene-acrylic acid system because itaconic acid is bearing two carboxylic acid functional groups. IA has been shown to greatly induce the thermal decomposition of potassium persulfate initiator due to its carboxyl functional groups. ${ }^{36}$ This may result in the increased entry of radicals into the polymer particles (Table IV) in addition to increased termination of these radicals in the aqueous phase. Furthermore, larger size of monomer swollen polymer particles in the particle growth stage (XPS4, Table V) can be result in the increased efficiency of radical entry into the each polymer particles and the concomitant decrease in the exit rate of radicals from the each polymer particles. Some evidence for higher value of $\bar{n}$ in the interval II of emulsion polymerization in the case of IA (XPS4) can also be observed in Figure 2 as an increased rate of polymerization in the particle growth stage (conversion between $0.1-0.4)$ relative to the particle nucleation stage (conversion below 0.1) in comparison with AA (XPS1). It should be noted that the formation of itaconic acid monomeric free-radicals in the particle phase by transfer reaction and thereby desorption of them from the polymer particles is negligible due to its very low solubility in the particle phase (Table II).

\section{CONCLUSION}

Emulsifier-free batch emulsion copolymerization of styrene-carboxylic acid monomer led us to some useful information about the influence of various carboxylic acid monomers on the kinetics of reaction in terms of the particle nucleation and growth processes. In this work, data obtained from DLS technique $\left(\mathrm{d}_{\text {pswol }}\right)$ were used to calculate $d_{p}$ and $N_{p}$ (kinetic parameter relating to the particle nucleation stage) for all the experiments from which the influence of carboxylic acid monomer type on particle growth stage $\left(\mathrm{R}_{\mathrm{p}} / \mathrm{N}_{\mathrm{p}}\right.$ and $\left.\bar{n}\right)$ was evaluated.

SEM studies showed that $\mathrm{N}_{\mathrm{p}}$ is almost constant in the particle growth stage (conversion above 10\%). This allows us to calculate the average number of propagating radical per particle $(\bar{n})$. It was found that average monomer swollen particles diameter at the same conversion had direct proportionality with hydrophilicity of carboxylic acid monomer type. Beside that, number of polymer particles and polymerization rate decreased with increasing hydrophilicity of carboxylic acid monomer. Also the effect of various carboxylic acid monomers on polymerization rate per particle $\left(\mathrm{R}_{\mathrm{p}} / \mathrm{N}_{\mathrm{p}}\right)$ and average number of propagating radicals per particle $(\bar{n})$ was investigated as a function of $\mathrm{d}_{\mathrm{pswol}}$ at the same conversion. It was deduced that the carboxylic acid monomer type has a significant effect on both particle nucleation $\left(N_{p}\right)$ and growth $\left(\mathrm{R}_{\mathrm{p}} / \mathrm{N}_{\mathrm{p}}\right.$ or $\left.\bar{n}\right)$ processes.

Acknowledgment. Thanks to my wife $\mathrm{M}$. Sharifpour for encouragement to complete this work.

\section{REFERENCES}

1. K. Sakota and T. Okaya, J. Appl. Polym. Sci., 20, 1745 (1976).

2. K. Sakota and T. Okaya, J. Appl. Polym. Sci., 20, 3265 (1976).

3. A.-R. Mahdavian and M. Abdollahi, Polymer, 45, 3233 (2004).

4. B.-Z. Yang, L.-W. Chen, and W.-Y. Chiu, Polym. J., 29, 737 (1997). 
5. M. Slawinski, J. Meuldijk, A. M. Van Herk, and A. L. German, J. Appl. Polym. Sci., 78, 875 (2000).

6. M. Slawinski, M. A. J. Schellekens, J. Meuldijk, A. M. Van Herk, and A. L. German, J. Appl. Polym. Sci., 76, 1186 (2000).

7. G. L. Shoaf and G. W. Poehlein, J. Appl. Polym. Sci., 42, 1213 (1991).

8. G. L. Shoaf and G. W. Poehlein, J. Appl. Polym. Sci., 42, 1239 (1991).

9. X.-Y. Yuan, V. L. Dimonie, E. D. Sudol, and M. S. El-Aasser, Macromolecules, 35, 8346 (2002).

10. X.-Y. Yuan, V. L. Dimonie, E. D. Sudol, and M. S. El-Aasser, J. Appl. Polym. Sci., 88, 1988 (2003).

11. X.-Y. Yuan, V. L. Dimonie, E. D. Sudol, J. E. Roberts, and M. S. El-Aasser, Macromolecules, 35, 8356 (2002).

12. B. S. Hawkett, D. H. Napper, and R. G. Gilbert, J. Chem. Soc. Faraday Trans., 76, 1323 (1980).

13. M. Slawinski, Strategic aspects of incorporation of acrylic acid in emulsion polymers; Ph.D. Thesis, Eindhoven University of Technology, 1999.

14. W. D. Harkins, J. Amer. Chem. Soc., 69, 1428 (1947).

15. M. Martines, "Safe Handling and Storage of Styrene", revision 1, Chevron Phillips Chemical Company LP, 2005, p 3.

16. S. Kim, Ph.D. Thesis, University of Akron, 1990.

17. R. Z. Greenley, J. Macromol. Sci., Chem., A14, 427 (1980).

18. F. V. Loncar, Analysis, Kinetics and Alkali-Swellability of Carboxylated Latexes. Ph.D. Thesis in Emulsion Polymers Institute, Lehigh University Bethlehem, PA, 1985.

19. A.-R. Mahdavian, M. Abdollahi, L. Mokhtabad, H. R. Bijanzadeh, and F. Ziaee, J. Appl. Polym. Sci., 101, 2062 (2006).

20. M. Buback, R. G. Gilbert, R. A. Hutchinson, B. Klumperman, F.-D. Kuchta, B. G. Manders, K. F. O'driscoll, G. T. Russel, and J. Schweer, Macromol. Chem. Phys., 196, 3267 (1995).

21. V. F. Gromov, N. I. Galperina, T. O. Osmanov, P. M. Khomikovskii, and A. D. Abkin, Eur. Polym. J., 16, 529 (1978).

22. S. Beuermann, D. A. Paquet, J. H. McMinn, and R. A. Hutchinson, Macromolecules, 30, 194 (1997).

23. L. H. Yee, M. Coote, R. P. Chaplin, and T. P. Davis, J. Polym. Sci., Part A: Polym. Chem., 38, 2192 (2000).

24. K. Sakota and T. Okaya, J. Appl. Polym. Sci., 20, 2583 (1976).

25. B. R. Vijayendran, J. Appl. Polym. Sci., 23, 893 (1979).

26. T. Alfrey and G. Goldfinger, J. Chem. Phys., 12, 205 (1944).

27. F. R. Mayo and J. Lewis, J. Amer. Chem. Soc., 66, 1594 (1944).

28. E. F. J. Verdurmen-Noel, Monomer partitioning and composition drift in emulsion copolymerization; Ph.D. Thesis, Eindhoven University of Technology, 1994.

29. W. H. Lane, Ind. Eng. Chem. Anal. Ed., 18, 295 (1946).
30. B. Jacobi, Angew. Chem., 64, 539 (1952).

31. W. J. Priest, J. Phys. Chem., 56, 1077 (1952).

32. R. M. Fitch and C. H. Tsai, in "Polymer colloids" R. M. Fitch, Ed., Plenum Press, New York, 1971, p 73.

33. J. Ugelstad and F. K. Hansen, Rubber Chem. Technol., 49, 536 (1976).

34. G. W. Ceska, J. Appl. Polym. Sci., 18, 427 (1974).

35. W. V. Smith and R. H. Ewart, J. Chem. Phys., 16, 592 (1948).

36. M. R. Lock, M. S. El-Aasser, A. Klein, and J. W. Vanderhoff, J. Appl. Polym. Sci., 39, 2129 (1990).

\section{APPENDIX}

$X_{\mathrm{ov}}(t)$ : Overall mass conversion at time $t$

$S C(t)$ : Solid content at time $t$

$S C_{(\text {initial })}$ : Solid content at the beginning of reaction

$S C_{(\text {final })}$ : Solid content at the end of reaction

$R_{p}$ : Polymerization rate per unit volume of the continuous phase

$C_{M, 0}$ : Initial monomer concentration

$\theta(t)$ : Overall molar conversion at time $t$

$\bar{k}_{p}$ : Average propagation rate coefficient in the particle phase

$\bar{n}$ : Average number of propagating radicals per particle

$N_{p}$ : Number of latex particles per unit volume of the aqueous phase

$C_{M P}$ : Overall monomer concentration in the polymer particles at interval II

$C_{M P}^{\prime}$ : Overall monomer concentration in the polymer particles at interval III

$N_{a v}$ : Avogadro's number

$P / W$ : Weight ratio of polymer to water

$M / W$ : Weight ratio of monomer(s) to water

$\rho_{P}$ : Average density of the polymer

$\rho_{W}$ : Density of water

$\rho_{M}$ : Density of the swelling monomer

$d_{p}$ : Average particle diameter

$d_{\text {pswol }}$ : Average diameter of monomer swollen particles

$M_{M}$ : Molecular weight of the swelling monomer

$f_{i}$ : Instantaneous mole fraction of monomer $i$ in the feed (unreacted monomer)

$r_{i}$ : Reactivity ratio of monomer $i$

$k_{p, i i}$ : Coefficient of propagation rate in homopolymerization of monomer $i$

$k_{p, j j}$ : Coefficient of propagation rate in homopolymerization of monomer $j$

$\alpha_{i}$ : Partition coefficient of carboxylic acid monomer $i$ between styrene and water 